\title{
Series Preface
}

The study of English literature in the early twenty-first century is host to an exhilarating range of critical approaches, theories and historical perspectives. 'English' ranges from traditional modes of study such as Shakespeare and Romanticism to popular interest in national and area literatures such as the United States, Ireland and the Caribbean. The subject also spans a diverse array of genres from tragedy to cyberpunk, incorporates such hybrid fields of study as Asian American literature, Black British literature, creative writing and literary adaptations, and remains eclectic in its methodology.

Such diversity is cause for both celebration and consternation. English is varied enough to promise enrichment and enjoyment for all kinds of readers and to challenge preconceptions about what the study of literature might involve. But how are readers to navigate their way through such literary and cultural diversity? And how are students to make sense of the various literary categories and periodisations, such as modernism and the Renaissance, or the proliferating theories of literature, from feminism and marxism to queer theory and eco-criticism? The Edinburgh Critical Guides to Literature series reflects the challenges and pluralities of English today, but at the same time it offers readers clear and accessible routes through the texts, contexts, genres, historical periods and debates within the subject.

Martin Halliwell and Andy Mousley 